\title{
Attributing Historical Changes in Probabilities of Record-Breaking Daily Temperature and Precipitation Extreme Events
}

\author{
Hideo Shiogama ${ }^{1}$, Yukiko Imada ${ }^{2}$, Masato Mori ${ }^{4}$, Ryo Mizuta $^{2}$, Dáithí Stone ${ }^{5}$, \\ Kohei Yoshida ${ }^{2}$, Osamu Arakawa ${ }^{6}$, Mikiko Ikeda ${ }^{7}$, Chiharu Takahashi ${ }^{3}$, \\ Miki Arai ${ }^{3}$, Masayoshi Ishii ${ }^{2}$, Masahiro Watanabe ${ }^{3}$ and Masahide Kimoto ${ }^{3}$ \\ ${ }^{1}$ Center for Global Environmental Research, National Institute for Environmental Studies, Tsukuba, Japan \\ ${ }^{2}$ Meteorological Research Institute, Tsukuba, Japan \\ ${ }^{3}$ Atmosphere and Ocean Research Institute, the University of Tokyo, Kashiwa, Japan \\ ${ }^{4}$ Research Center for Advanced Science and Technology, the University of Tokyo, Tokyo, Japan \\ ${ }^{5}$ Computational Research Division, Lawrence Berkeley National Laboratory, Berkeley, USA \\ ${ }^{6}$ Faculty of Life and Environmental Sciences, University of Tsukuba, Tsukuba, Japan \\ ${ }^{7}$ Japan Agency for Marine-Earth Science and Technology, Yokohama, Japan
}

\begin{abstract}
We describe two unprecedented large (100-member), longterm (61-year) ensembles based on MRI-AGCM3.2, which were driven by historical and non-warming climate forcing. These ensembles comprise the "Database for Policy Decision making for Future climate change (d4PDF)". We compare these ensembles to large ensembles based on another climate model, as well as to observed data, to investigate the influence of anthropogenic activities on historical changes in the numbers of record-breaking events, including: the annual coldest daily minimum temperature $(\mathrm{TNn})$, the annual warmest daily maximum temperature (TXX) and the annual most intense daily precipitation event (Rxlday). These two climate model ensembles indicate that human activity has already had statistically significant impacts on the number of record-breaking extreme events worldwide mainly in the Northern Hemisphere land. Specifically, human activities have altered the likelihood that a wider area globally would suffer record-breaking TNn, TXx and Rx1day events than that observed over the 20012010 period by a factor of at least $0.6,5.4$ and 1.3 , respectively. However, we also find that the estimated spatial patterns and amplitudes of anthropogenic impacts on the probabilities of record-breaking events are sensitive to the climate model and/or natural-world boundary conditions used in the attribution studies.

(Citation: Shiogama, H., Y. Imada, M. Mori, R. Mizuta, D. Stone, K. Yoshida, O. Arakawa, M. Ikeda, C. Takahashi, M. Arai, M. Ishii, M. Watanabe, and M. Kimoto, 2016: Attributing historical changes in probabilities of record-breaking daily temperature and precipitation extreme events. SOLA, 12, 225-231, doi:10.2151/ sola.2016-045.)
\end{abstract}

\section{Introduction}

In recent years, record-breaking extreme weather and climate events have occurred in many places around the world (Coumou and Rahmstorf 2012; WMO 2013; WMO 2015), attracting the interest of the general public, the scientific community and policy makers. Certain record-breaking events have caused major human suffering and financial losses (WMO 2014). It is extremely likely that human influences have been the dominant cause of the observed mean warming trend since the mid-20th century (Bindoff et al. 2013). However, it remains unclear whether human activities are also to blame for the occurrence of new record-breaking extreme events. How have human activities significantly affected

Corresponding author: Hideo Shiogama, Center for Global Environmental Research, National Institute for Environmental Studies, 16-2 Onogawa, Tsukuba, Ibaraki 305-8506, Japan. E-mail: shiogama.hideo@nies.go.jp. (C)2016, the Meteorological Society of Japan. probabilities of record-breaking extreme events?

Previous studies have investigated the ratio of record high temperatures to record low temperatures averaged over certain regions. Meehl et al. (2009) found that the ratio of record-high daily maximum temperatures to record-low daily minimum temperatures averaged across the U.S. increased to approximately two (an observational product) or four (a climate model) from 1950 to 2006. Elguindi et al. (2013) and Lewis and King (2015) found that the ratio of record-high maximum temperatures to recordlow minimum temperatures across Europe (seasonally averaged data) and Australia (monthly and annually averaged data) has also increased in recent decades. The number of local record-breaking monthly temperature extremes identified globally is now five times larger than would be expected in a climate not experiencing long-term warming trends, as estimated by a statistical model (Coumou et al. 2013). The statistically significant trends in increasing annual maximum daily precipitation values can be detected at many stations around the world (Westra et al. 2013), and the number of global record-breaking daily rainfall events is $12 \%$ greater than that anticipated by a theoretical stationary time series (Lehmann et al. 2015).

The aforementioned results imply that external factors have influenced these record-breaking events. Historical and separated forcing simulations (e.g., natural-forcing-only simulations) of a coupled atmosphere-ocean global climate model (CGCM) (Bindoff et al. 2013) would allow researchers to formally attribute the increase in the frequency of record-breaking events to human activities. Previous studies (Christidis et al. 2005; Shiogama et al. 2006; Min et al. 2011; Min et al. 2013) have attributed long-term annual maximum and minimum daily temperature trends and annual maximum daily precipitation trends to historical anthropogenic changes in greenhouse gases concentrations and aerosol emissions using the optimal fingerprinting technique (Allen and Stott 2003) and outputs from CGCM attribution experiments. Lewis and King (2015) analyzed the outputs of historical and natural-only CGCM simulations contributed to the Coupled Model Inter-comparison Project phase 5 (CMIP5) and suggested that human activities have increased the frequency of record-high temperatures in Australia. Bador et al. (2016) showed that the 10-member natural-only ensemble of the CNRM-CM5 CGCM failed to reproduce the observed increases in the number of record-breaking daily temperature events across Europe while the 10 -member ensemble driven by natural and anthropogenic forcing was compatible with the observed changes.

Recently a new approach using atmospheric global climate model (AGCM) simulations has been developed to quantify human impacts on the likelihood and magnitude of a single extreme event (Pall et al. 2011; Christidis et al. 2013; Shiogama et al. 2013; Shiogama et al. 2014). In this AGCM-based probabilistic event attribution approach, two large ensembles of factual historical-forcing and counterfactual natural-forcing (e.g., 
100-members each) are produced, generally for short time periods. Larger ensemble sizes and the possibility of higher spatial resolutions using AGCM ensembles can allow more precise estimates of how changes in the frequency and magnitude of extreme events occur than can CGCM simulations. On the other hand, the AGCM-based approach has certain limits. Atmosphere-ocean interactions are not included in the AGCM-based approach, nor are the possible effects of anthropogenic forcing on ocean variability. Therefore we cannot test if the observed climate change can occur only due to the internal variability in the coupled atmosphere-ocean system. Furthermore, limitations in computing resources typically result in short-term experimental periods (from one season to a few years) and prevent long-term trend analyses.

In this study, we analyze large, long-term ensembles of factual and counterfactual climate forcing using a high-resolution AGCM, MRI-AGCM3.2 (horizontal resolution of approximately $60 \mathrm{~km}$ ) (Mizuta et al. 2012). Together with a future projection ensemble and downscaling experiments, these ensembles are being called the "Database for Policy Decision making for Future climate change (d4PDF)" (Mizuta et al. 2016). The first aim of this paper is to describe the experimental design of the d4PDF's attribution experiments. We compared the d4PDF's outputs with other large, long-term ensembles of NCAR CAM5.1-1degree AGCM ( $\sim 100 \mathrm{~km})$ (Neale et al. 2010) conducted under the C20C+ Detection and Attribution Sub-project (Angélil et al. 2016). This is the first multi-AGCM attribution study to investigate long-term changes in the frequency of record-breaking daily temperature and precipitation events.

\section{Experimental setup and extreme indices}

The d4PDF ensembles (Mizuta et al. 2016) are comprised of 100-member "all forcing" (ALL) runs and 100-member "nonwarming trends" (NW) runs. Simulations were run for the 19502010 period. The ALL runs were forced by observed sea surface temperature (SST) and sea ice (SIC) of COBE-SST2 (Hirahara et al. 2014) and also included historical changes in well-mixed greenhouse gas (GHG) concentrations, ozone, anthropogenic aerosol burdens (sulfate, black carbon and organic carbon), volcanic sulfate aerosol loading (specifically from the Pinatubo eruption) and natural aerosol loading (sea salt and dust). Solar irradiance variations were excluded from the study. We added random small, spatio-temporally continuous perturbations to the monthly SSTs to account for monitoring uncertainties in actual SST values (Mizuta et al. 2016). The spread of random SST perturbations was kept constant throughout the experimental period. These random fluctuations induced chaotic perturbations in atmospheric variability. The NW ensemble included SST data, excluding the first principal component mode of the historical SST change, which is similar to the linear trend pattern (i.e., we approximately removed the linear trends in SST). The SIC in the NW runs were estimated using an empirical quadratic relationship between SST-SIC (Hirahara et al. 2014; Mizuta et al. 2016). We used GHG concentrations, anthropogenic aerosol and volcanic sulfate aerosol values of 1850 , and 1961 ozone concentrations. Although differences between the ALL and NW ensembles contain not only anthropogenic factors but also natural forcing (solar and volcanic) signals on SST/SIC and internal atmospheric variability, it was expected that anthropogenic factors would have a much larger impact than natural factors (solar and volcanic forcing) in the long-term analyses. We also ran a 90 -member future time-slice ensemble where we added SST change patterns of $+4^{\circ} \mathrm{C}$ global warming taken from 6 CMIP5 CGCMs to the NW SST and using 2090 conditions of the RCP8.5 scenario (van Vuuren et al. 2011) (Mizuta et al. 2016). These historical and future AGCM simulations were also dynamically downscaled around Japan by using a $20-\mathrm{km}$ resolution reginal climate model. However, we did not analyze the future projections or regional downscaling simulations in this work. The d4PDF output data are available on the Data Integration and Analysis System (DIAS) website (http://www.diasjp.net/en/).

The Lawrence Berkeley National Laboratory (LBNL) climate research group previously produced the ALL and natural forcing (NAT) CAM5.1 ensembles for the 1959-2014 period (Angélil et al. 2016). The ALL runs were forced by SSTs and SICs from the Hurrell et al. (2008) product updated with NOAA OI.v2 (Reynolds et al. 2002), GHG concentrations, anthropogenic aerosol burdens (sulfate, black carbon and organic carbon), ozone, solar irradiance, volcanic aerosol concentrations, land-use changes and natural aerosol burdens (sea salt and dust). In the NAT runs, GHG, anthropogenic aerosol and ozone values of 1855 were used. The anthropogenic changes in SST and SIC diagnosed using the CMIP5 multi-CGCM historical and natural forcing simulations were removed (Stone and Pall 2016). These simulations were performed within the $\mathrm{C} 20 \mathrm{C}+$ Detection and Attribution Sub-project, and the output data are available from http://portal.nersc.gov/ $\mathrm{c} 20 \mathrm{c} /$.

The ALL runs of these two AGCMs capture the observed annual mean land temperature changes at the continental scale, while the NW and NAT runs do not reproduce the warming anomalies observed over the last 15-20 years (Fig. 1). Figure 2 shows the SST differences between ALL and NW (NAT) averaged for the 2001-2010 period. The SST difference for CAM5.1 has larger warming in the Arctic that that in d4PDF (Fig. 2), and the CAM5.1 ensemble appears to overestimate warming attributable to anthropogenic factors in the Arctic, such that a notable cooling and sea ice expansion trend can be seen in the NAT simulations (Figs. 1g, 1i, and 1k).

In the next section, we investigate the annual lowest daily minimum temperature ( $\mathrm{TNn}$ ), the annual highest daily maximum temperature (TXx) and the annual highest daily precipitation (Rx1day) values identified in the model simulations and an observational product (HadEX2, Donat et al. 2012) for the 1959-2010 period. The horizontal resolution of the simulated extreme indices was interpolated using a HadEX2 $3.75^{\circ} \times 2.5^{\circ}$ longitude-latitude grid. The simulated data were discarded when observations were not available for certain times or locations. Grids missing data for more than 26 years (the half of the 52-year analyzed period) were filled with a missing value. As seen in Fig. 3, the available data were almost exclusively located in the Northern Hemisphere, and the spatial coverage for precipitation is much more limited than that for temperature. See Donat et al. (2012) for additional details on the distribution of the data. We examined the numbers of new records for TNn (record cold events), TXx (record hot events) and Rx1day (record intense rain events).

\section{Results}

The frequencies of record-setting events are expected to decrease as observations accumulate over time (Meehl et al. 2009). Figure 4 shows the evolution of the area fraction of recordbreaking extreme events relative to the global area where observed data are available (i.e. how many percent of the observed area shown in Fig. 3 suffer new record-breaking events for each year), given the analysis period starting in 1959. The ensemble averaged ALL runs for both AGCMs reproduced the varying rates of decline in the observed TNn, TXx and Rx1dy. The NAT and NW runs exhibited faster rates of decline for TXx and slower rates for TNn than the ALL runs and the observed data. The differences between the averaged values for the ALL and NW ensembles within the d4PDF are essentially continuously significant after 1983 and 1978 for TNn and TXx, respectively. For the temperature extremes, the CAM5.1 ensembles show larger differences between ALL and NAT than that in d4PDF, mainly due to differences in the rate in CAM5.1's NAT ensemble which likely reflect its Arctic cooling trend. Differences in the ALL and NAT ensembles of CAM5.1 are essentially continuously significant after 1974 and 1979 for TNn and TXx, respectively. The points of continuously significant changes in temperature extremes were similar for TXX but there was a 9-year difference in TNn values between these two models.

The NAT and NW runs have faster decline rates of Rx1day than the ALL runs and the observed data. The differences between 
(a) North America, d4PDF

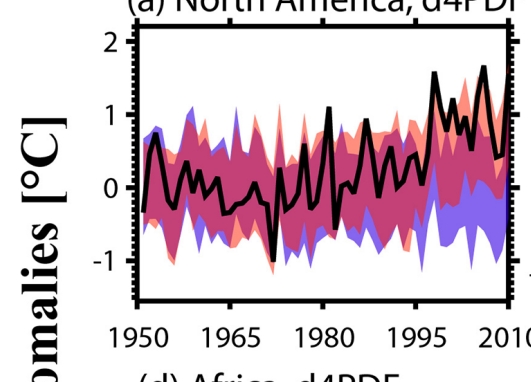

(b) South America, d4PDF

(c) Europe, d4PDF
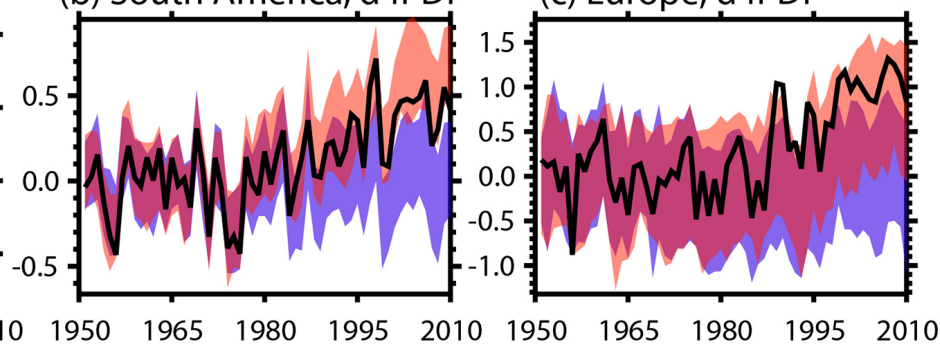

(d) Africa, d4PDF

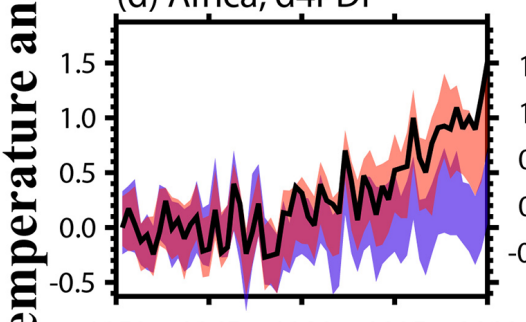

(e) Asia, d4PDF
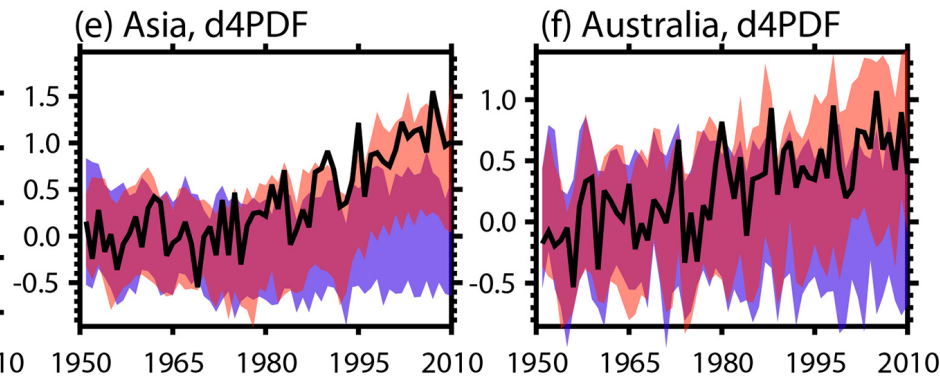

(g) North America, CAM5.1

(h) South America, CAM5.1

(i) Europe, CAM5.1
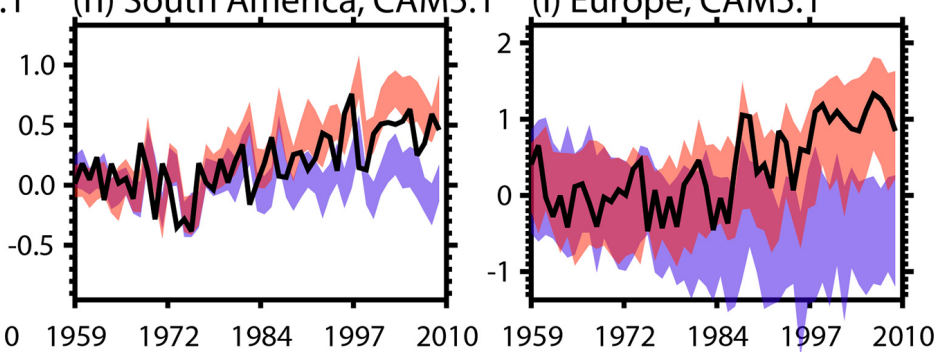

$1959 \quad 1972 \quad 1984 \quad 1997 \quad 2010$

(k) Asia, CAM5.1

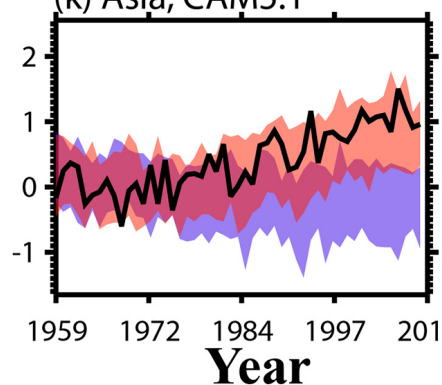

(l) Australia, CAM5.1

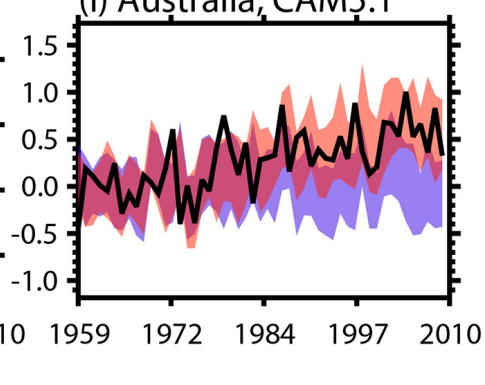

Fig. 1. Continental mean annual surface air temperature changes $\left({ }^{\circ} \mathrm{C}\right)$. Black lines represent observed conditions (Jones et al. 2012). Red and blue shading indicate the minimum-maximum ranges of the ALL and NW (NAT) ensembles, respectively. Panels (a)-(f) denote the d4PDF ensembles during 1951-2010 (anomalies from the 1951-1970 mean). Panels (g)-(1) denote the regional CAM5.1 ensembles during 1959-2010 (anomalies from the 1959-1978 mean). See Giorgi (2002) for definitions of the continental regions.

(a)d4PDF

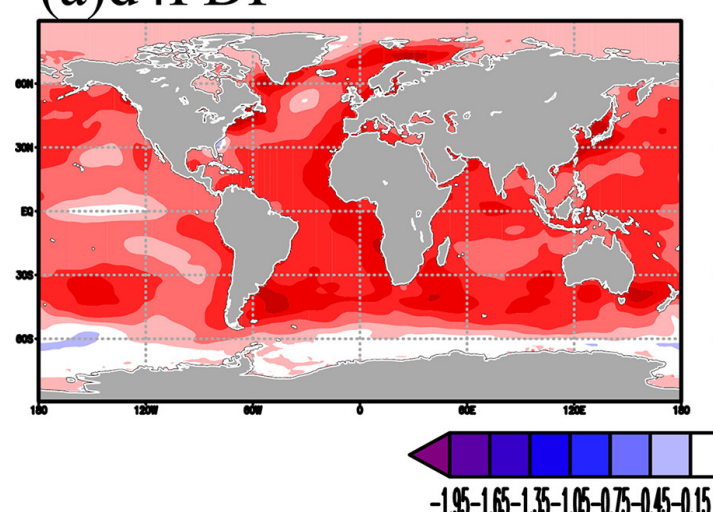

(b)CAM5.1

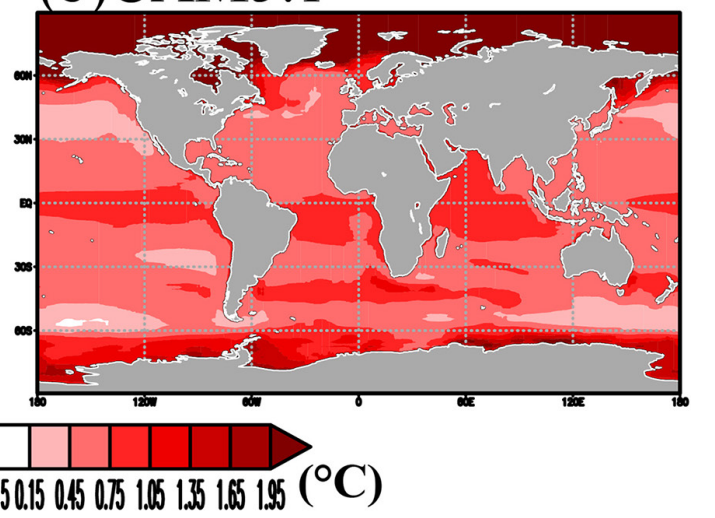

Fig. 2. Sea surface temperature differences $\left({ }^{\circ} \mathrm{C}\right.$ ) between (a) ALL and NW for d4PDF and (b) ALL and NAT for CAM5.1 during 2000-2010. 
(a)TNn, d4PDF

(d)TNn, CAM5.1

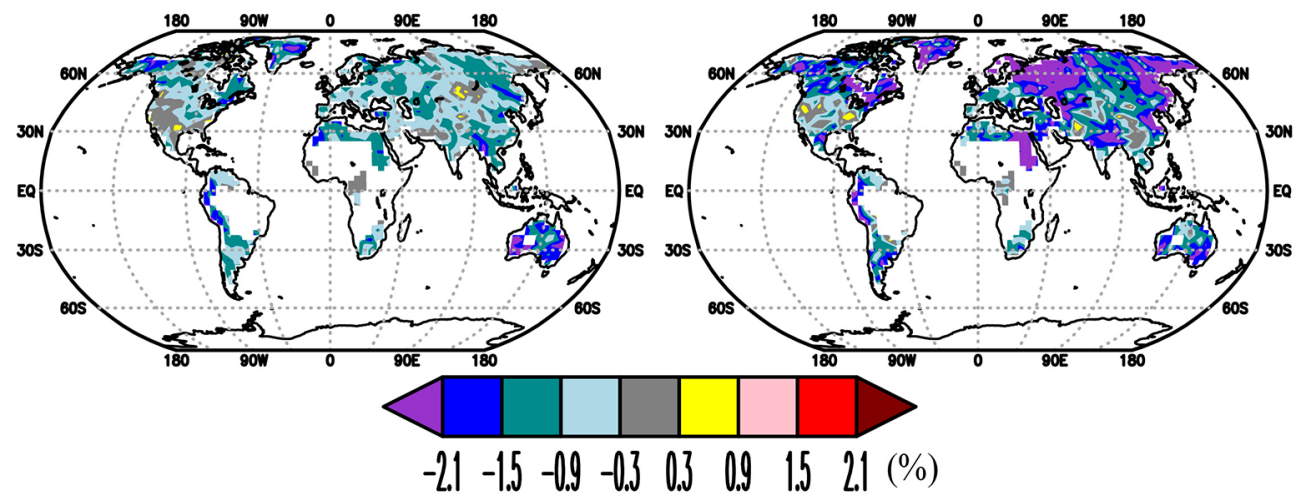

(b)TXx, d4PDF

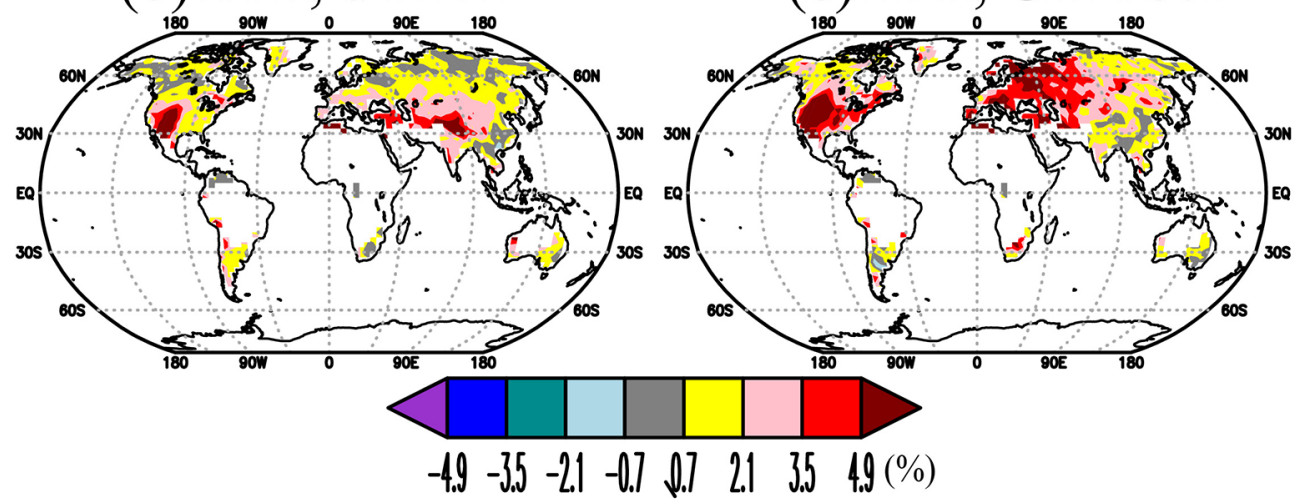

(c)Rx1day, d4PDF

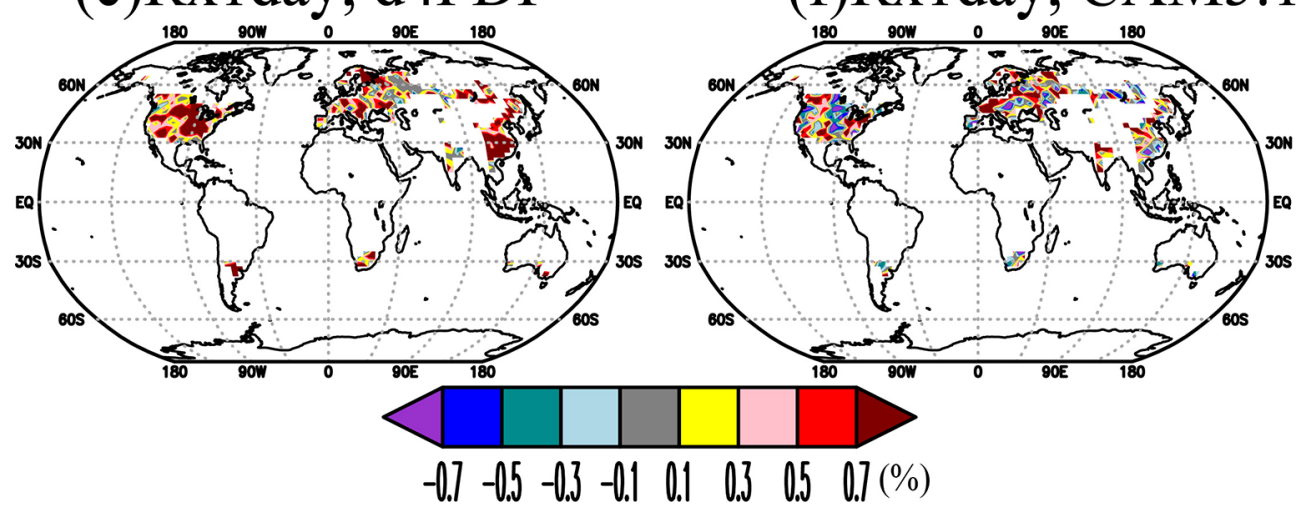

Fig. 3. Geographical distributions of differences in the record setting probabilities between ALL and NW (NAT) during the 2001-2010 period (\%). (a) TNn, (b) TXx and (c) Rx1day for d4PDF; and (d) TNn, (e) TXx and (f) Rx1day for CAM5.1. The white areas indicate grid cells where recorded data were not sufficient.

the ensemble averaged values of Rx1day for ALL and NW of d4PDF are essentially continuously significant after 1996. The differences in Rx1day values in the CAM5.1 ensembles were smaller than those in the d4PDF. Although there were some significant differences in Rx1day values between the CAM5.1 ALL and NAT ensembles, the difference was not significant in 2010. It is not clear why the Rx1day differences in CAM5.1 are smaller than that of d4PDF.

Figure 5 displays the normalized histograms of the area fraction of record-breaking extreme events that occurred during the 2001-2010 period (we compute area fractions for each of 10-year $\times 100$ (50) members and make the histograms). The red ALL distributions of TXX and Rxlday shift rightward and widen relative to the blue NAT and NW distributions. As the distributions move leftward, their width should decrease because the lower bound must be greater than or equal to zero by definition. The mean area fractions of record-breaking TNx significantly decrease from $2.17 \%$ to $1.14 \%$ for $\mathrm{d} 4 \mathrm{PDF}$ and from $2.90 \%$ to $1.04 \%$ for CAM5.1 (Table 1). The mean area fractions of record-breaking TXx significantly increase by $2.40 \%$ (d4PDF) and $3.19 \%$ (CAM 5.1 ). The mean area fractions of record-breaking Rx1day also significantly rose by $0.62 \%$ (d4PDF) and $0.26 \%$ (CAM5.1). The black vertical lines represent the area fractions of observed record-breaking events averaged across the 2001-2010 period. Human activity has increased "the likelihood of a wider area would be affected by record-breaking TXx than the observed value" by 6.2 -fold in average (the $10 \%-90 \%$ range for the 1000-time bootstrap resampling is 5.4-7.2) for d4PDF and 11-fold (8-14) for CAM5.1. Here we randomly sample "10 years $\times 100(50)$ members" with replacement and compute ratios between ALL and NW (NAT) by 1000- 


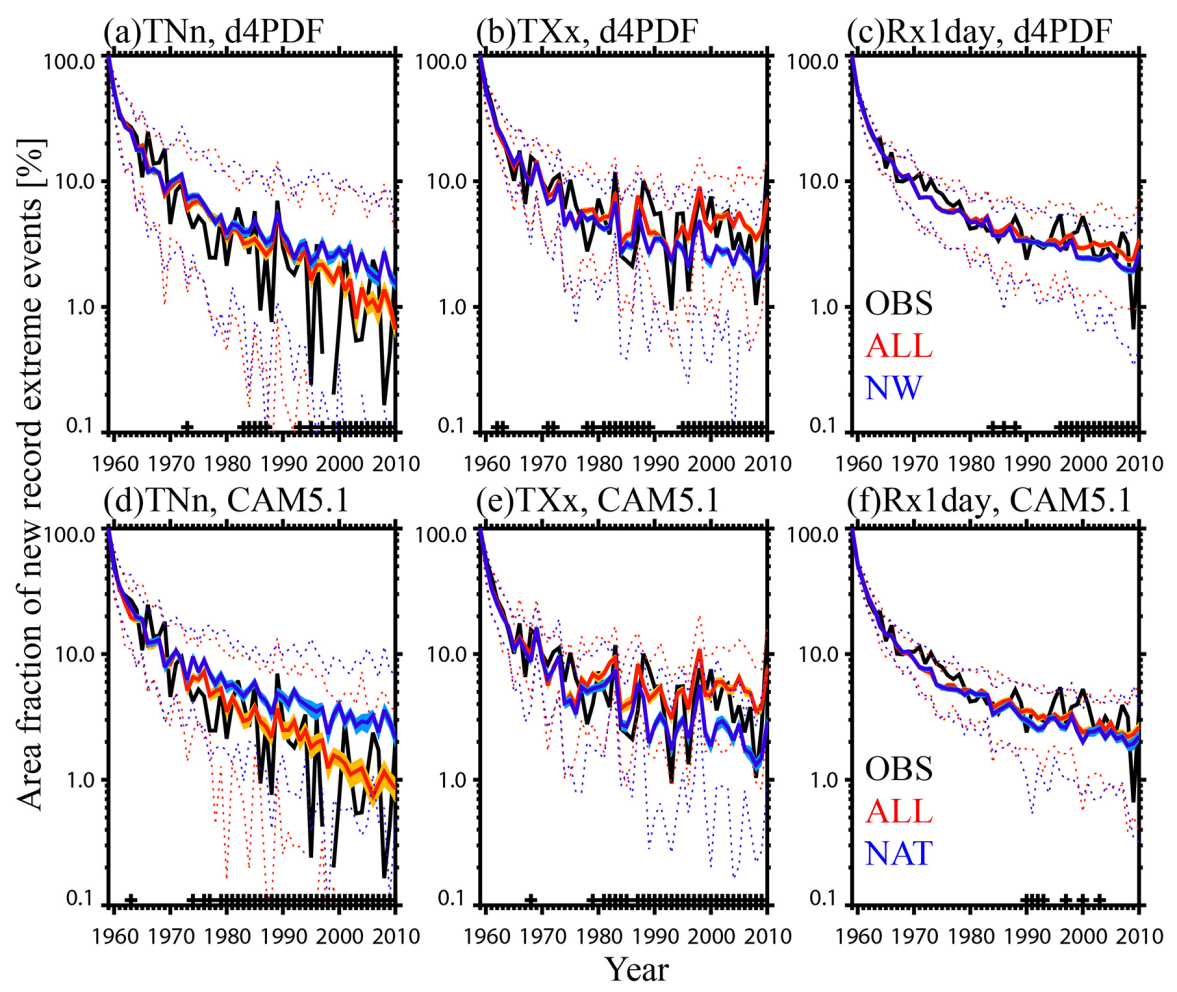

Fig. 4. The temporal evolution of the fraction of the global area where record-breaking events occurred. (a, d) TNn, (b, e) TXx and (c, f) Rx1day for HadEX2 (black), ALL (red) and NW or NAT (blue) (\%), where 1959 was the beginning of the analysis period. The top panels represent the d4PDF simulations and the bottom panels show the CAM5.1 simulations. The solid red and blue lines denote the ensemble averages. The yellow and light blue shading represent the $10 \%-90 \%$ confidence intervals of the ensemble averages. Crosses indicate the differences between the ensemble mean ALL and NW (NAT) are statistically significant at the $\pm 10 \%$ level using the t-test. The dotted lines represent the max-min ranges of the ensemble members.

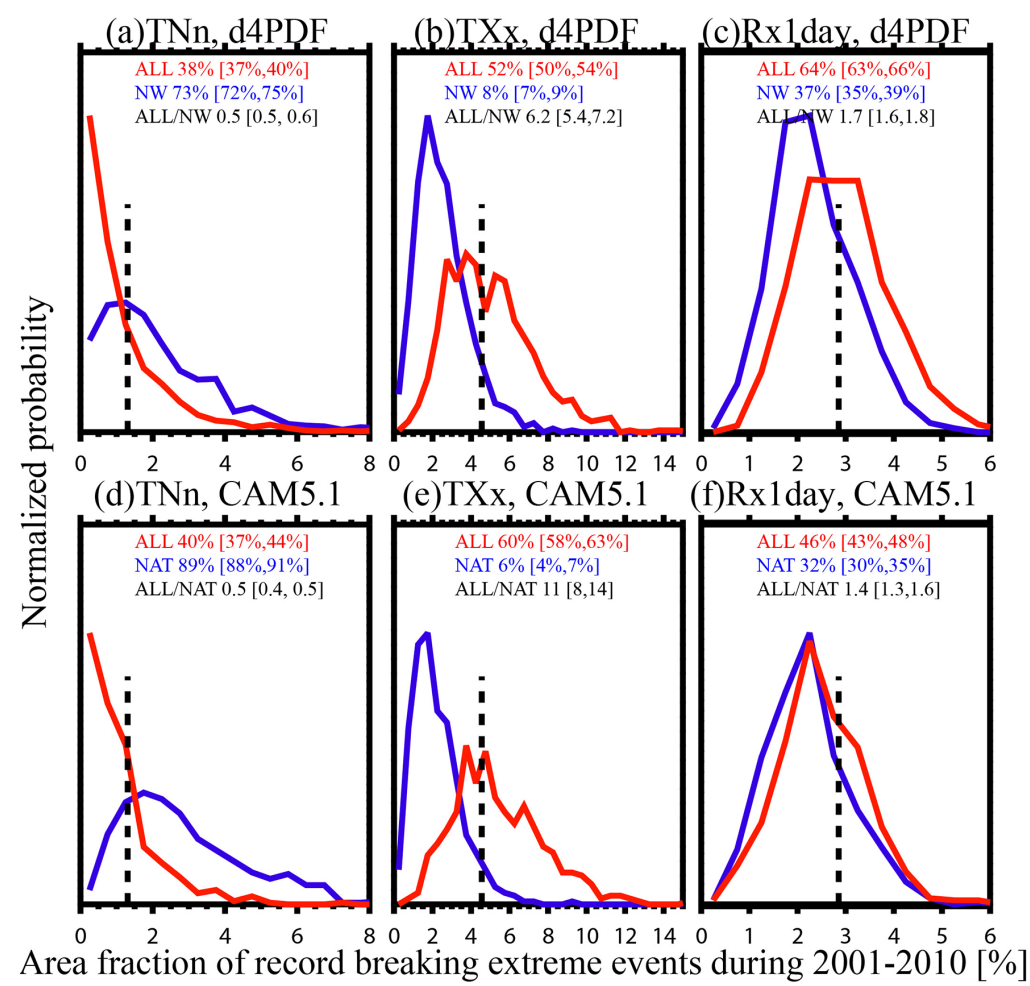

Fig. 5. The red and blue distributions represent the normalized histograms $(0.5 \%$ bins $)$ of the fraction of the area with record breaking events during the 2001-2010 period for ALL and NW (NAT), respectively. (a) TNn, (b) TXx and (c) Rx1day for d4PDF, respectively; (d) TNn, (e) TXx and (f) Rx1day for CAM5.1, respectively. The black dotted lines are the observed area fractions of record-breaking event averaged over the $2001-2010$ period. The red and blue numbers show the probabilities that area fractions of ALL and NW (NAT) are larger than the observed values, respectively (\%). The black numbers indicate the ratios between ALL/NW (ALL/NAT) (no unit). The brackets show the $10 \%-90 \%$ uncertainty ranges computed by the 1000 -time bootstrap resampling. 
Table 1 . Averages and the corresponding 10\%-90\% confidence intervals (based on t-tests) of the fraction of the area with record breaking events during the 2001-2010 period for TNn, TXx and Rx1day of d4PDF and CAM5.1.

\begin{tabular}{cccc}
\hline & TNn & TXx & Rx1day \\
\hline ALL, d4PDF & $1.14 \%$ & $4.93 \%$ & $2.94 \%$ \\
& {$[1.05 \%, 1.22 \%]$} & {$[4.51 \%, 5.36 \%]$} & {$[2.90 \%, 2.98 \%]$} \\
\hline NW, d4PDF & $2.17 \%$ & $2.53 \%$ & $2.32 \%$ \\
& {$[1.98 \%, 2.36 \%]$} & {$[2.43 \%, 2.63 \%]$} & {$[2.30 \%, 2.34 \%]$} \\
\hline ALL, CAM5.1 & $1.04 \%$ & $5.41 \%$ & $2.49 \%$ \\
& {$[0.99 \%, 1.10 \%]$} & {$[4.63 \%, 6.18 \%]$} & {$[2.45 \%, 2.53 \%]$} \\
\hline NAT, CAM5.1 & $2.90 \%$ & $2.22 \%$ & $2.23 \%$ \\
& {$[2.57 \%, 3.23 \%]$} & {$[2.10 \%, 2.33 \%]$} & {$[2.20 \%, 2.27 \%]$} \\
\hline
\end{tabular}

times to estimate the uncertainty ranges. In contrast, the likelihood that a wider area would be affected by record-breaking TNn than has been observed is halved: the ratios of ALL and NW (NAT) are $0.5(0.5-0.6)$ and $0.5(0.4-0.5)$ for d4PDF and CAM5.1, respectively. Human activities have significantly increased the likelihood that a wider area will be affected by record-breaking Rxlday than has been observed by 1.7 -fold (1.6-1.8) and 1.4fold (1.3-1.6) for d4PDF and CAM5.1, respectively. Although the annual Rx1day statistics in CAM5.1 show that human activities had a non-significant impact on the frequency of record extremes in some years between 2001-2010 (Fig. 4f), the 10-year aggregated analysis (Fig. $5 \mathrm{f}$ and Table 1) provides stronger evidence for the anthropogenic contribution to more frequent record-breaking Rxlday events.

Figure 3 shows the geographical distributions of differences in record setting probabilities between ALL and NW (NAT) during the 2001-2010 period. For both climate models, the occurrence probabilities of record-breaking $\mathrm{TNn}$ decreased in most areas with sufficient data, while those of TXx and Rxlday increased. However, the spatial patterns and the amplitudes of the probability changes differed between the models. For example, large increases in record-breaking TXx probabilities were found across Europe and in western Siberia using the CAM5.1 ensembles, while changes identified in the d4PDF ensembles were moderate in these regions. On the other hand, both models indicated distinct increases in the likelihood of record-breaking TXx in the southwestern United States. These results suggest the importance of multiple AGCM intercomparison studies for probabilistic event attributions and long-term trend analyses, and suggest that uncertainties in counterfactual ocean conditions should be considered; in particular, the European and western Siberian excesses identified in the CAM5.1 are consistent with the Arctic cooling in the NAT SST and SIC estimates used. Quantitative attribution of local record-breaking events can be sensitive to differences in the AGCMs and estimates of counterfactual boundary conditions.

\section{Summary and discussions}

We have produced unprecedented large, long-term ensembles using the hi-resolution MRI AGCM, which we compile into the "Database for Policy Decision making for Future climate change (d4PDF)" (Mizuta et al. 2016). We described the experimental setup of the historical and the non-warming experiments of d4PDF, which is briefly explained in Mizuta et al. (2016) and Kamae et al. (2016).

This is also the first study that has compared large-size longterm attribution experiments using two AGCMs, specifically MRIAGCM3.2 and CAM5.1, to investigate the impacts of anthropogenic factors on historical changes in the frequencies of recordbreaking daily temperature and precipitation extreme indices. Declining frequencies in record-breaking annual coldest night events and increasing numbers of record-breaking annual warmest day events, along with increasing intense precipitation events around the world (mainly in the Northern Hemisphere land) were found. Lewis and King (2015) and Bador et al. (2016) have suggested human influences as a primary cause of changes in the number of record-breaking temperature events in Australia and Europe, respectively. We revealed that human activity has already had a statistically significant effect on historical changes in the numbers of record-breaking daily cold events, hot events and intense rain events over the world's continents generally. Anthropogenic climate change has increased the probabilities that a wider area globally may have suffered record-breaking TXX and Rx1day than was observed during the 2001-2010 period, by at least 5.4-fold and 1.3-fold, respectively, and has decreased that of TNn by at least 0.6 -fold.

However, it has also been suggested that the estimated amplitudes and spatial patterns of human impacts on record-breaking events are sensitive to the models used. It has been shown that the assessments of AGCM-based probabilistic event attribution of local extreme events can depend on assumptions made in counterfactual experiments (Shiogama et al. 2014; Imada et al. 2014). Therefore, multi-model analyses with different assumptions of counterfactual experiments are important for regional attribution studies of long-term trends of extreme events and single events. The outputs of the two AGCMs presented here are available to the public for free, and simulations of other AGCMs (although primarily focused on short-term periods) are also provided by the C20C+ Detection and Attribution Sub-project. These open-access datasets can facilitate the more robust attribution of extreme events.

\section{Acknowledgments}

We thank two reviewers for the useful comments. The Earth Simulator was used to run the d4PDF simulations for JAMSTEC's "Strategic Project with Special Support". This study was supported by the Program for Risk Information on Climate Change (SOUSEI) and the Data Integration and Analysis System (DIAS), both of which are sponsored by the Ministry of Education, Culture, Sports, Science and Technology, Japan. The CAM5.1 simulations were supported by the US Department of Energy Office of Science, Office of Biological and Environmental Research, under contract number DE-AC02-05CH11231.

Edited by: R. Kawamura

\section{References}

Allen, M. R., and P. A. Stott, 2003 Estimating signal amplitudes in optimal fingerprinting, part I: theory. Climate Dyn., 21, 477491.

Angelil, O., D. Stone, M. Wehner, C. J. Paciorek, H. Krishnan, and W. Collins, 2016: An independent assessment of anthropogenic attribution statements for recent extreme weather. $J$. Climate, submitted.

Bador, M., L. Terray, and J. Boé, 2016: Detection of anthropogenic influence on the evolution of record-breaking temperatures over Europe. Climate Dyn., 45, 2717-2735.

Bindoff, N. L., P. A. Stott, K. M. AchutaRao, M. R. Allen, N. Gillett, D. Gutzler, K. Hansingo, G. Hegerl, Y. Hu, S. Jain, I. I. Mokhov, J. Overland, J. Perlwitz, R. Sebbari, and X. Zhang, 2013: Detection and Attribution of Climate Change: from Global to Regional. Climate Change 2013: The Physical Science Basis. Contribution of Working Group I to the Fifth Assessment Report of the Intergovernmental Panel on Climate Change, Stocker, T. F., D. Qin, G.-K. Plattner, M. Tignor, S. K. Allen, J. Boschung, A. Nauels, Y. Xia, V. Bex, and P. M. Midgley, Eds., Cambridge University Press, Cambridge, United Kingdom and New York, NY, USA.

Christidis, N., P. A. Stott, S. Brown, G. C. Hegerl, and J. Caesar, 2005: Detection of changes in temperature extremes during 
the second half of the 20th century. Geophys. Res. Lett., 32, L20716, 1-4.

Christidis, N., and co-authors, 2013: A new HadGEM3-A-Based System for attribution of weather- and climate-related extreme events. J. Climate, 26, 2756-2783.

Collins, M., R. Knutti, J. Arblaster, J.-L. Dufresne, T. Fichefet, P. Friedlingstein, X. Gao, W. J. Gutowski, T. Johns, G. Krinner, M. Shongwe, C. Tebaldi, A. J. Weaver, and M. Wehner, 2013: Long-term Climate Change: Projections, Commitments and Irreversibility. Climate Change 2013: The Physical Science Basis. Contribution of Working Group I to the Fifth Assessment Report of the Intergovernmental Panel on Climate Change, Stocker, T. F., D. Qin, G.-K. Plattner, M. Tignor, S. K. Allen, J. Boschung, A. Nauels, Y. Xia, V. Bex, and P. M. Midgley, Eds., Cambridge University Press, Cambridge, United Kingdom and New York, NY, USA.

Coumou, D., and S. Rahmstorf, 2012: A decade of weather extremes. Nature Climate Change, 2, 491-496.

Coumou, D., A. Robinson, and S. Rahmstorf, 2013: Global increase in record-breaking monthly-mean temperatures. Climatic Change, 118, 771-782.

Donat, M. G., and co-authors, 2013: Updated analyses of temperature and precipitation extreme indices since the beginning of the twentieth century: The HadEX2 dataset. J. Geophys. Res. Atmos., 118, 2098-2118, doi:10.1002/jgrd.50150.

Elguindi, N., S. Rauscher, and F. Giorgi, 2013: Historical and future changes in maximum and minimum temperature records over Europe. Climatic Change, 117, 415-431.

Giorgi, F., 2002: Variability and trends of sub-continental scale surface climate in the 20th century. Part I: Observations. Climate Dyn., 18, 675-691.

Hirahara, S., M. Ishii, and Y. Fukuda, 2014: Centennial-scale sea surface temperature analysis and its uncertainty. J. Climate, 27, 57-75.

Imada, Y., H. Shiogama, M. Watanabe, M. Mori, Y. Kamae, M. Ishii, and M. Kimoto, 2014: The contribution of anthropogenic forcing to the Japanese heat waves of 2013, in "Explaining Extreme Events of 2013 from a Climate Perspective". Bull. Amer. Meteor. Soc., 95, S52-S54.

Jones, P. D., D. H. Lister, T. J. Osborn, C. Harpham, M. Salmon, and C. P. Morice, 2012: Hemispheric and large-scale land surface air temperature variations: An extensive revision and an update to 2010. J. Geophys. Res., 117, D05127, doi: 10.1029/2011JD017139

Kamae, Y., H. Shiogama, Y. Imada, M. Mori, O. Arakawa, R. Mizuta, K. Yoshida, C. Takahashi, M. Arai, M. Ishii, M. Watanabe, M. Kimoto, S.-P. Xie, and H. Ueda, 2016: Forced response and internal variability of summer climate over western North America. Climate Dyn., submitted.

Lehmann, J., D. Coumou, and K. Frieler, 2015: Increased recordbreaking precipitation events under global warming. Climatic Change, 132, 501-515.

Lewis, S. C., and A. D. King, 2015: Dramatically increased rate of observed hot record breaking in recent Australian temperatures. Geophys. Res. Lett., 42, 7776-7784.

Meehl, G. A., C. Tebaldi, G. Walton, D. Easterling, and L. McDaniel, 2009: Relative increase of record high maximum temperatures compared to record low minimum temperatures in the U. S., Geophys. Res. Lett., 36, L23701.

Min, S.-K., X. Zhang, F. W. Zwiers, and G. C. Hegerl, 2011: Human contribution to more-intense precipitation extremes. Nature, 470, 378-381.

Min, S.-K., X. Zhang, F. Zwiers, H. Shiogama, Y.-S. Tung, and
M. Wehner, 2013: Multimodel detection and attribution of extreme temperature changes. J. Climate, 26, 7430-7451.

Mizuta, R., H. Yoshimura, H. Murakami, M. Matsueda, H. Endo, T. Ose, K. Kamiguchi, M. Hosaka, M. Sugi, S. Yukimoto, S. Kusunoki, and A. Kitoh, 2012: Climate simulations using MRI-AGCM with 20-km grid. J. Meteor. Soc. Japan, 90A, $235-260$.

Mizuta, R., and co-authors, 2016: Over 5000 years of ensemble future climate simulations by $60 \mathrm{~km}$ global and $20 \mathrm{~km}$ regional atmospheric models. Bull. Amer. Meteor. Soc., submitted.

Neale, R. B., and co-authors, 2010: Description of the NCAR community atmosphere model (CAM 5.0). NCAR Tech. Note NCAR/TN-486+ STR.

Pall, P., and co-authors, 2011: Anthropogenic greenhouse gas contribution to flood risk in England and Wales in autumn 2000. Nature, 470, 380-384.

Rayner, N. A., D. E. Parker, E. B. Horton, C. K. Folland, L. V. Alexander, D. P. Rowell, E. C. Kent, and A. Kaplan, 2003: Global analyses of sea surface temperature, sea ice, and night marine air temperature since the late nineteenth century. $J$. Geophys. Res., 108, D14, 4407, doi:10.1029/2002JD002670.

Reynolds, R. W., N. A. Rayner, T. M. Smith, D. C. Stokes, and W. Wang, 2002: An improved in situ and satellite SST analysis for climate. J. Climate, 15, 1609-1625.

Shiogama, H., N. Christidis, J. Caesar, T. Yokohata, T. Nozawa, and S. Emori, 2006: Detection of greenhouse gas and aerosol influences on changes in temperature extremes. SOLA, 2 , $152-155$.

Shiogama, H., M. Watanabe, Y. Imada, M. Mori, M. Ishii, and M. Kimoto, 2013: An event attribution of the 2010 drought in the South Amazon region using the MIROC5 model. Atmos. Sci. Lett., 14, 170-175.

Shiogama, H., M. Watanabe, Y. Imada, M. Mori, Y. Kamae, M. Ishii, and M. Kimoto, 2014: Attribution of the June-July 2013 heat wave in the Southwestern United States. SOLA, 10, $122-126$.

Stone, D. A., and P. Pall, 2016: A benchmark estimate of the effect of anthropogenic emissions on the ocean surface. $J . A d v$. Model. Earth Sys., submitted.

UK Met Office, 2015: Flooding in Cumbria December 2015 (Available online at http://www.metoffice.gov.uk/climate/uk/ interesting/december2015, accessed on 26 July 2016).

van Vuuren, D. P., J. Edmonds, A. Thomson, K. Riahi, M. Kainuma, T. Matsui, G. C. Hurtt, J.-F. Lamarque, M. Meinshausen, S. Smith, C. Granier, S. K. Rose, and K. A. Hibbard, 2011: Representative concentration pathways: An overview. Climate Change, 109, 5-31.

Westra, S., L. V. Alexander, and F. W. Zwiers, 2013: Global increasing trends in annual maximum daily precipitation. $J$. Climate, 26, 3904-3918.

World Meteorological Organization, 2013: WMO Provisional Statement on Status of the Climate in 2013. World Meteorological Organization, $18 \mathrm{pp}$.

World Meteorological Organization, 2014: Atlas of Mortality and Economic Losses from Weather, Climate and Water Extremes (1970-2012). World Meteorological Organization, 48 pp.

World Meteorological Organization, 2015: WMO Provisional Statement on Status of the Climate in 2015. World Meteorological Organization.

Manuscript received 26 April 2016, accepted 2 July 2016

SOLA: https://www.jstage.jst.go.jp/browse/solal 